EESTI NSV TEADUSTE AKADEEMIA TOIMETISED. XVIII KÖIDE

KEEMIA * GEOLOOGIA. 1969, NR. 3

ИЗВЕСТИЯ АКАДЕМИИ НАУК ЭСТОНСКОИ ССР. ТОМ ХVIII

Химия * ГЕОЛОГИя. 1969, № 3

Э. ВОРОБЬЕВA

\title{
К МОРФОЛОГИИ ЩЕЧНОЙ ОБЛАСТИ PANDERICHTHYS RHOMBOLEPIS (GROSS)
}

В 1966 г. автором совместно с Л. Лярской, сотрудницей Управления геологии Латвии, было открыто новое местонахождение рыб среднегауйского возраста в правом борту реки Абава (Латвия) у хут. Новадниеки. Остатки рыб здесь имеют довольно хорошую сохранность и встречаются по всему разрезу обнажающихся пород мощностью около $4 \mu$. Наибольшее число их отмечается на высоте $1 M$ от уреза воды в светлосерых и желто-серых разнозернистых плохосортированных песчаниках и приурочено к цепочкам глинистой гальки и линзовидным прослоям мелкогалечного конгломерата. Здесь найдено несколько крупных щитов и чешуи псаммостеид (преимущественно Psammolepis alata, peже Psammolepis paradoxa), в большом количестве обломки панцирей антиарх (Asterolepis ornata) и несколько артродир (Plourdosteus sp.), шипы плавников акантодов (Archaeacanthus quadrisulcatus, Haplacanthus ehrmanensis), покрывные кости черепа дипной (Dipterus crassus), чешуи, изолированные зубы и фрагменты черепа кистеперых.

Кистеперые (Crossopterygii) представлены чешуями остеолепидид (Osteolepididae inc. gen.), чешуями, изолированными зубами и обломками костей голоптихоидей (Onychodus sp., Glyptolepis baltica, Laccognathus panderi); передней половиной нижней челюсти и частью париетального щита Eusthenopteron sävesöderberghi; чешуями, фрагментами челюсти и неполной щечной пластиной Panderichthys rhombolepis. Последний вид в виде чешуи, зубов и остатков нижней челюсти описывался ранее из гауйских и аматских слоев Главного девонского поля: Эстония (Вастселийна), Латвия (реки Брасла, Рауна, Гауя, Даугава и окрестности Цесиса), Литва (реки Армона, Швентойи), Ленинградская область (р. Оредеж у дер. Горынь, Ям-Тесово, Милодеж и р. Тесовая у дер. Бойково).

Находка щечной пластины Panderichthys rhombolepis представляет особый интерес, поскольку щечная область у Panderichthys (монотипического рода сем. Panderichthyiidae подотр. Osteolepidoidei) ранее не была известна, а ее строению у кистеперых рыб придается немаловажное таксономическое значение.

Судя по имеющейся большей передней части, длина пластины не менее 150 мм, высота 75 мм, диаметр глазницы около 20 мм. Бо́льшую часть нижнего края глазницы составляет lacrimale (La; рисунок, таблица), от которого сохранилась небольшая задняя часть, налегающая на jugale (Ju). Последний занимает около $1 / 2$ высоты пластины и образует небольшой участок задне-нижнего края орбиты; отношение длины 
к высоте (1/ht Ju) 1,5. Шов с lacrimale довольно длинный, составляет 0,68 высоты jugale $\left(\frac{h t_{1}}{h t \text { Ju}}\right)$. Центр радиации находится вблизи нижнего края кости, где проходит горизонтальная часть инфраорбитального сенсорного канала (іос). Вертикальная часть этого канала пересекает переднюю половину кости и у ее верхнего края отклоняется несколько вперед, проходя на границе передней четверти postorbitale (Ро). Плошадка налегания maxillare тянется в виде желобка с гребенистой поверхностью по внутренней стороне нижнего края jugale (od. Mx, pисунок, $a$ ). Нижний край пластины прямой на границе jugale и lacrimale и изогнут вниз под углом $120-130^{\circ}$ на границе jugale и squamosum. Судя по форме этого края, maxillare достигало наибольшей высоты в своей задней половине, образуя по верхнему краю единственный, по-видимому, угол на границе squamosum и jugale. Отношение наибольшей высоты пластины в области postorbitale к расстоянию от вершины этого максиллярного угла до задне-нижнего края орбиты равно 1,3.

Вытянутое и очень низкое postorbitale [отношение длины к высоте $(1 /$ ht $\mathrm{Po}=3,2)]$ составляет задний край глазницы. Верхний край кости сильно выпуклый посередине, задний образует острый угол. На внутренней стороне вдоль верхнего края развиты очень широкие и перекрывающие друг друга площадки для intertemporale (od. It) и dermosphenoticum (od. Dsph). Площадка налегания на наружной стороне верхнего края орбиты, по-видимому, двойная. Ее передняя широкая часть предназначалась, очевидно, для supraorbitale posterior (od. $\mathrm{So}_{2}$, рисунок, б), задняя - маленькая и узкая, пересекаемая инфраорбитальным каналом, для dermosphnoticum (od. Dsph). Supraorbitale posterior, образующая верхний край глазницы, не граничила с jugale и lacrimale.

Центр радиации squamosum $(\mathrm{Sq})$ находится в передне-нижней половине кости и, по-видимому, пересекается югальным каналом (juc), продолжающим горизонтальную ветвь инфраорбитального. Передне-верхний угол кости вклинивается между postorbitale и jugale.

Наличие единственного squamosum и прохождение югального сенсорного канала параллельно оральному краю черепа, свойственные щечной пластине Panderichthys rhombolepis, являются, по Э. Ярвику (Jarvik*), типично остеолепиформными чертами строения (характерными для подотряда Osteolepidoidei и отличающими последний от подотряда Holotychioidei).

По расположению, форме и перекрыванию костей передней половины щечной пластины, а также участию их в образовании орбиты Panderichthys rhombolepis наиболее сходен с представителями сем. Eusthenopteridae - Eusthenopteron foordi (Jarvik, 1944, фиг. 16, 17В), отличаясь пропорциями postorbitale, которое примерно в 1,5 раза ниже, чем у E. foordi, более передним положением вертикальной ветви инфраорбитального канала, более горизонтальным положением площадки на postorbitale для supraorbitale posterior и, следовательно, более наклонным положением переднего края последней кости. Вместе с тем по отдельным признакам (форма и пропорции костей, участие их в образовании орбиты, положение центров радиации сенсорных каналов) наблюдается сходство нашей формы с отдельными представителями сем. Osteolepididae, описанными Э. Ярвиком (Jarvik, 1948). Интересно отметить тот факт, что сходство в строении имеющейся части щечной пластины у Panderichthys rhombolepis и Eusthenopteron foordi значительно больше,

* Доклад на IV Международном нобелевском симпозиуме в Стоктольме в 1967 г. 
od. Dsph.

c.d. $\mathrm{SO}_{2}$

$a$

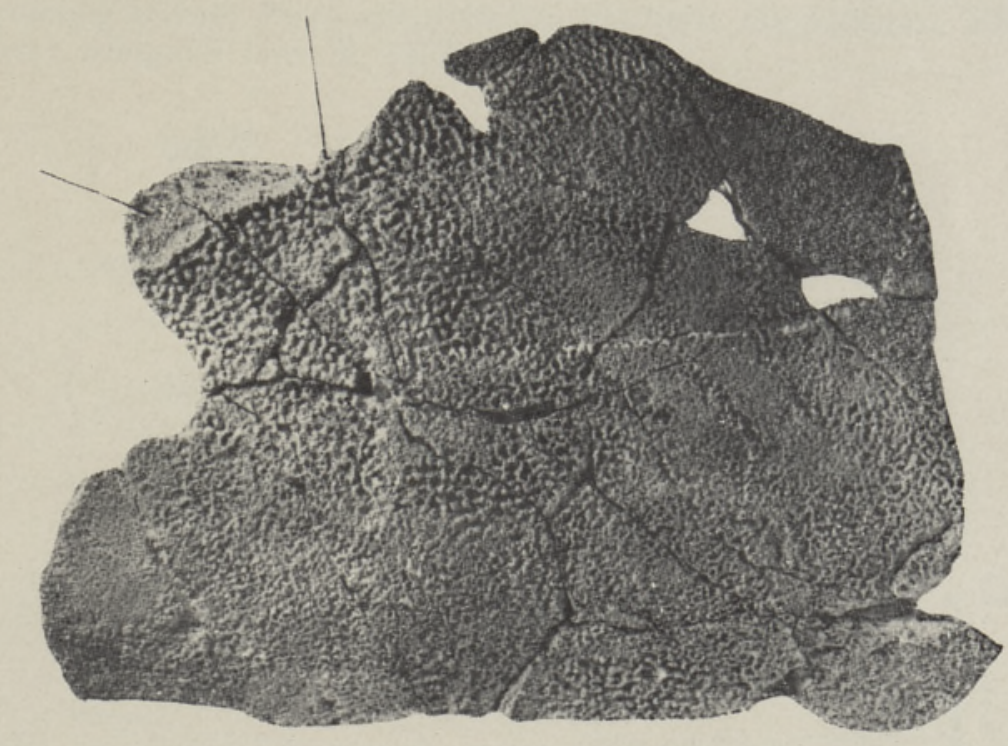

od. It

oá. Dsph.

ó

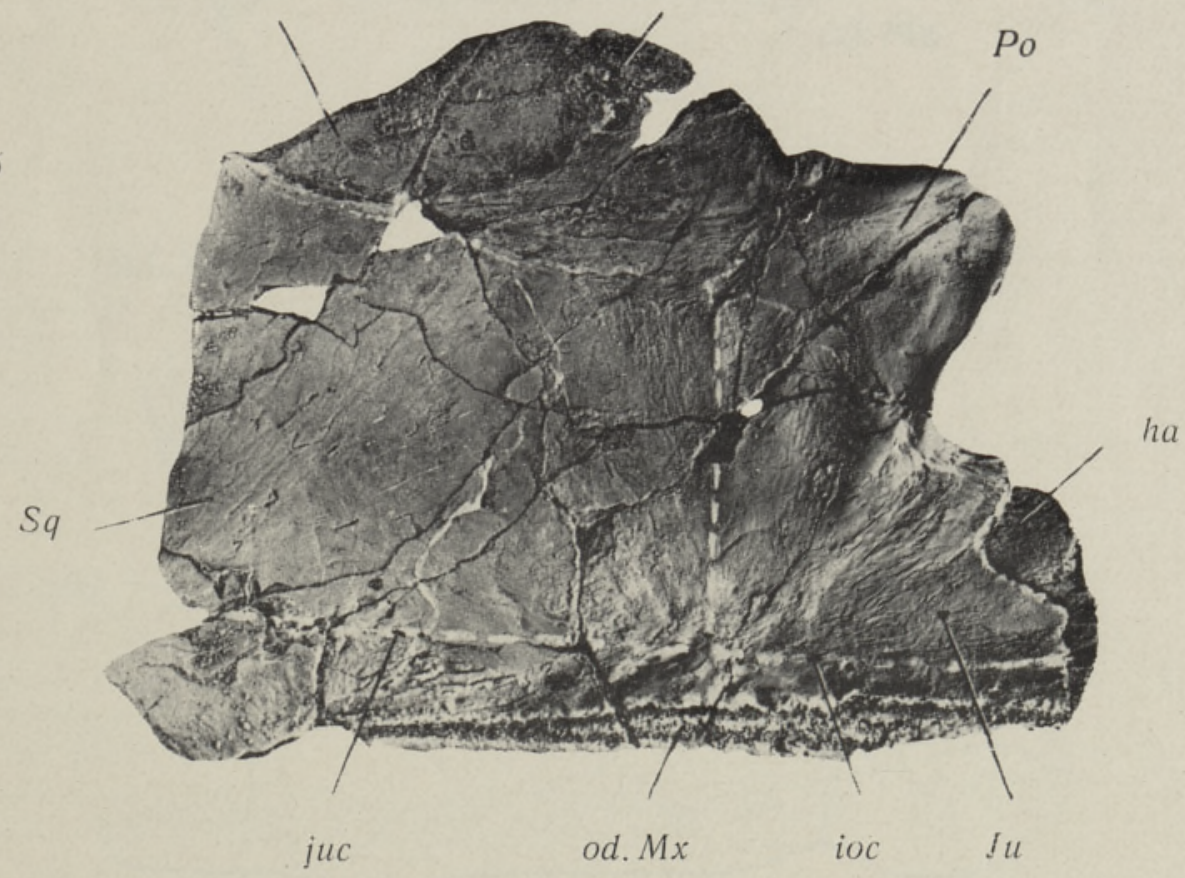

Panderichthys rhombolepis (Gross), щечная пластинка $(X 1)$ :

$a$ - снаружи, б - с внутренней стороны; среднегауйские слон. правый берег p. Абава у хут. Новадниеки, Латвия.

Объяснения обозначениї даны в подписях к рисунку. 

чем между последним и известными в этом отношении представителями сем. Eusthenopteridae: Platycephalichthys bischoffi (Воробьева, 1962) и Eusthenodon wängsjöi (Jarvik, 1952).

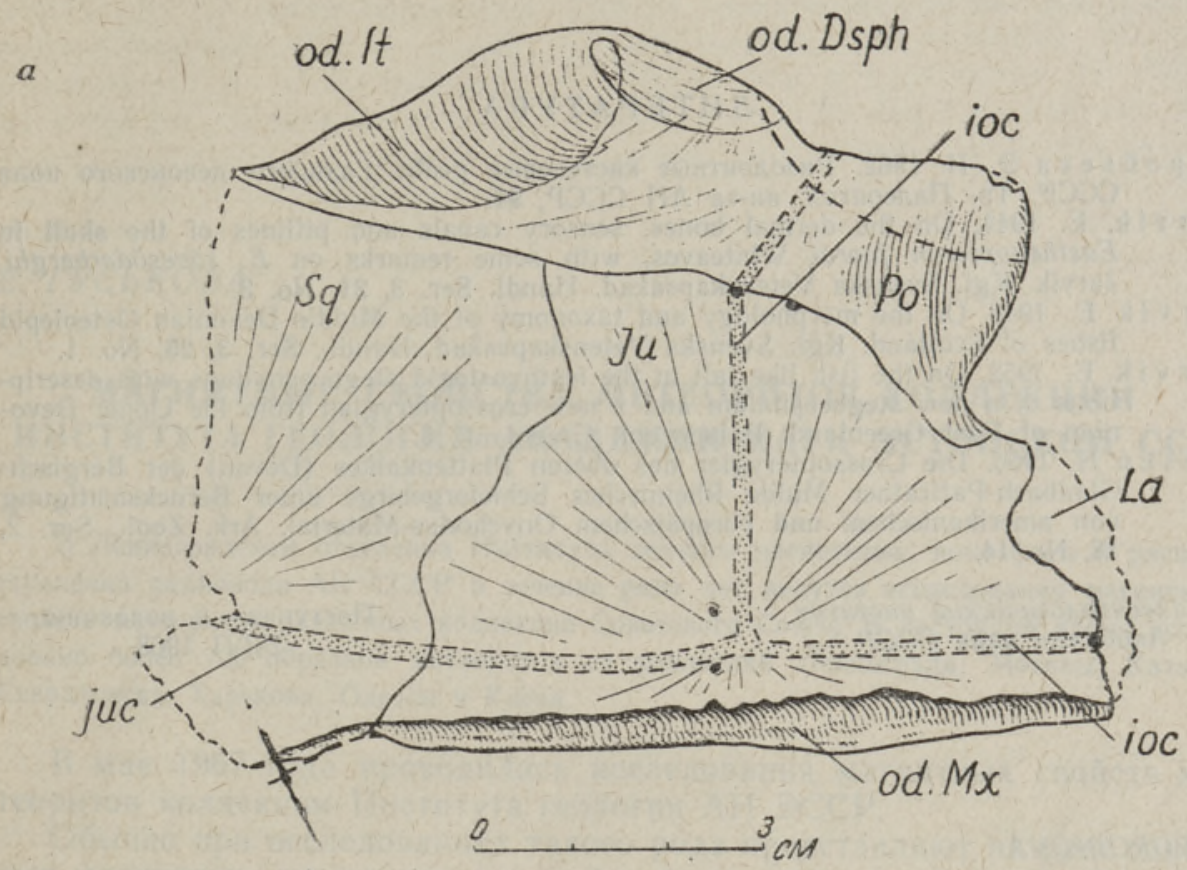

6

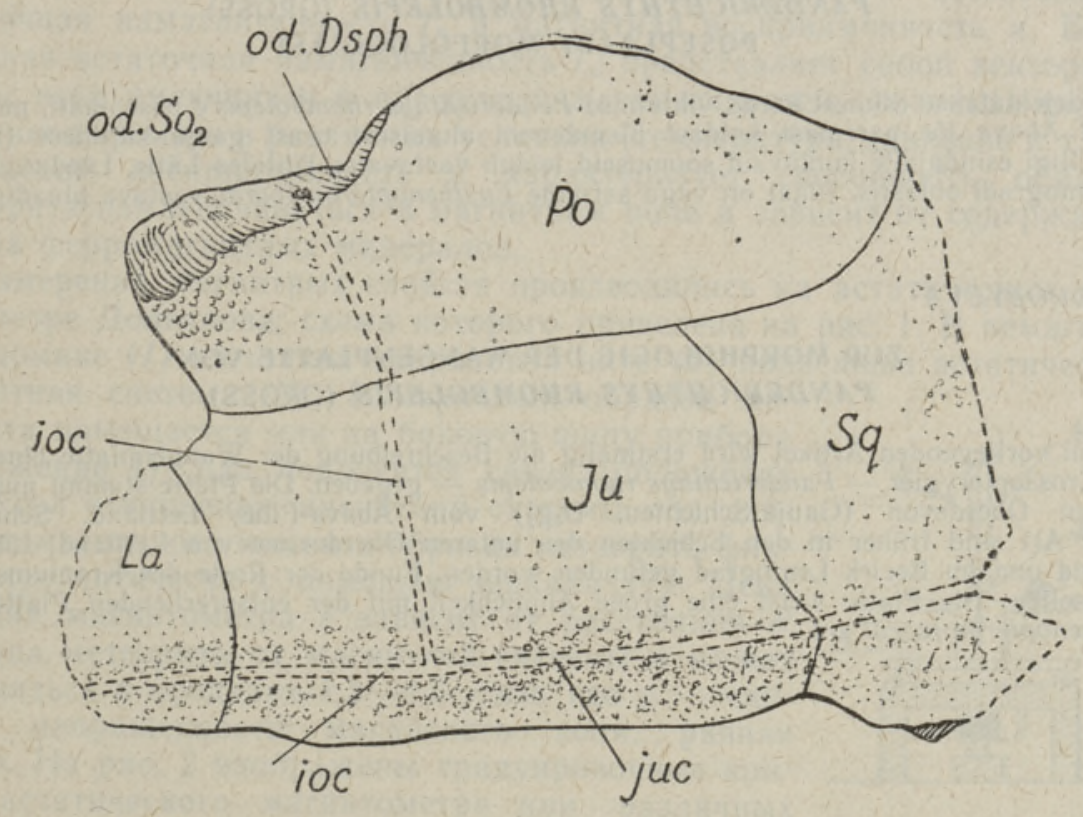

Щечная пластина Panderichthys rhombolepis П1Н № 54, X1:

$a$ - с внутренней стороны; 6 - снаружи; среднегауйские слои, правый берег

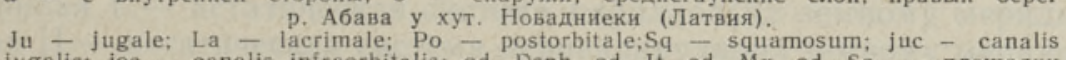
jugalis; ioc - canalis infraorbitalis; od. Dsph, od. It, od. Mx. od. So - площадки иалегания dermosphenoticum, intertemporale, maxillare, supraorbitale posterior 
По-видимому, таксономическая значимость особенностей строения щечной области кистеперых и, в частности, подотряда Osteolepidoideí может варьировать в разных семействах.

\section{ЛИТЕРАТ УРА}

В ороб ье в а Э. И. 1962. Ризодонтные кистеперые рыбы Главного девонского поля СССР. Тр. Палеонтол. ин-та АН СССР, 94.

Jarvik, E. 1944. On the dermal bones, sensory canals and pitlines of the skull in Eusthenopteron foordi Whiteaves, with some remarks on E. sävesöderberghi, Jarvik. Kgl. Svenska Vetenskapsakad. Handl. Ser. 3, 21, No. 3.

J a rvik E. 1948. On the morphology and taxonomy of the Middle Devonian Osteolepid fishes of Scotland. Kgl. Svenska Vetenskapsakad. Handl., Ser. 3, 25, No. 1.

J a rvik E. 1952. On the fish like tail in the ichthyostegid stegocephalians with descriptions of a new stegocephalian and a new crossopterygian from the Upper Devonian of East Greenland. Palaeozool. Greenland, 5.

Jessen'H. 1966. Die Crossopterygier des oberen Plattenkalkes (Devon) der BergischGladbach-Pafírather Mulde Rheinisches Schiefergebirge unter Berücksichtigung von amerikanischem und europäischem Onychodus-Material. Ark. Zool., Ser. 2, 18 , Nr. 14.

Палеонтологический институт Академии наук СССР

Поступила в редакцию 25/VI 1968

E. VOROBJOVA

\section{PANDERICHTHYS RHOMBOLEPIS (GROSS) PÕSEPLAADI MORFOLOOGIAST}

Kirjeldatakse esimest korda vihtuimse Panderichthys rhombolepis'e põseplaati, mis leitì Lätist Abava jōe paremast kaldast ülemdevoni alumisest osast gauja kihtidest $\left(D_{3} g j\right)$. Selle liigi esindajaile kuuluvaid soomuseid leidub vastavates kihtides Lätis, Leedus, Eestis ja Leningradi oblastis. Plaat on väga sarnane Eusthenopteron foordi vastava plaadiga.

\section{E. VOROBYEVA}

\section{ZUR MORPHOLOGIE DER WANGENPLATTE VON PANDERICHTHYS RHOMBOLEPIS (GROSS)}

Im vorliegenden Artikel wird erstmalig die Beschreibung der Wangenplatte einer Art von Crossopterygier - Panderichthys rhombolepis - gegeben. Die Platte stammt aus dem unteren Oberdevon (Gauja-Schichten, $D_{3} g j$ ) vom Abava-FluB, Lettland. Schuppen dieser Art sind früher in den Schichten des unteren Oberdevons von Lettland, Litauen, Estland und im Bezirk Leningrad gefunden worden. Funde der Reste des Kraniums sind sehr selten. Die Platte weist eine große Ahnlichkeit mit der entsprechenden Platte von Eusthenopteron foordi auf. 